\title{
Texto y contexto de dos manuscritos literarios inéditos del siglo XVIII escritos por sefardíes
}

\author{
KENNETH BROWN *
}

El propósito del presente estudio es el de describir y valorar nuevos manuscritos literarios escritos por sefardíes residentes en los Países Bajos en el siglo dieciocho. Nos interesan sus contextos históricos-literarios.

El primer texto (lámina 1) es el manuscrito 18.156 procedente de la Biblioteca Nacional de Madrid, Rato de plazer y coloquio de damas (Amberes 1708), novelita cortesana compuesta por un tal don Fileno, "Poeta de polvo y lodo". Según alusiones y referencias internas en el texto este "poeta de disparates que se las pagaba" " se llamaba FONSECA de apellido, ya que su hermana era Doña Beatriz de Fonseca. Un hermano suyo era de nombre Gabriel. Era tetuaní radicado en los Países Bajos. Si la «F» inicial o la "L» intervocálica del nombre pastoril del personaje principal y autor --el YO- de la novelita sea una indicación de su nombre auténtico, puede que se llamase «Felipe» o «León». Todo esto es pura especulación.

Tal códice consta en el Catálogo de los manuscritos que pertenecieron a D[on] Pascual de Gayangos existentes hoy en la Biblioteca Nacional (Madrid 1904), por D[on] Pedro Roca, pág. 233, n. ${ }^{\circ} 682$, y se describe así: «Es una novela burlesca escrita, no en 1508 como dice la portada, sino en 1708, si bien el estilo y la ortografía están indicando que fue algún judio o extranjero el que la compuso. Es obra, sin embargo, no falta de mérito, y los versos son bastantes buenos". El lomo lleva la fecha y el lugar de "Londres Agosto 1854", lo cual acaso señale ciudad y momento

* Millikin University. Illinois.

1 Real Academia Española, Diccionario de autoridades (Madrid, Gredos, 1979), tomo II. s.v. LOD, pág. 429, 2 a $^{\text {a }}$ col.: "De aquellos polvos vienen estos lodos". "Refr. que explica, que de qualquier yerro u desorden que se comete al executar alguna cosa, provienen los daños y males que después se siguen". 
de adquisición. Este texto, de una extensión de unos sesenta y cinco folios, es una obra híbrida: mezcla de sueño bocalinesco, novela pospicaresca, novelita cortesana al estilo de Castillo Solórzano, cancionero de buen gusto, y autorretrato burlesco de estirpe gongorina. Su pequeño cancionero así colocado entre secciones de prosa es "arcádico", aunque se encuentran a la vez rimas levemente burlonas. El fin del cancionero es cantar las gracias de una tal doña Anarda, cuyo pseudónimo seguramente destaca a una señorita o señora poco sensible a los requiebros del yo narrativo, y de sus dos «hermanas" igualmente pastoriles, Cintia y Clori. Se nos ofrecen rasgos de novela "à clef", pero se nos escapan todos los significados personales por nuestro alejamiento de los hechos. El YO del narrador se autorretrata como feo e indigno de doña Anarda, reminiscencia tal del «Polifemo" gongorino y del subgénero del autorretrato burlesco que parece nacer con don Luis ${ }^{2}$. En cierto modo convencional, pues, el Rato de plazer y coloquio de damas representa una extensión de obras en prosa que pudieron posibilitar la creación de El siglo pitagórico y Vida de don Gregorio Guadaña (Rouen 1644), del marrano o judaizante Antonio Enríquez Gómez ${ }^{3}$, y es importante subrayar que Fonseca cita a éste además de a Quevedo y Jacinto Polo de Medina como autores de inspiración. Rato de plazer es de lectura amena en partes - tal como señalaba don Pedro Roca- y las láminas que se reproducen a continuación de esta breve introducción a los textos certificarán, según creo, tales conclusiones.

El segundo manuscrito inédito es del Doctor David Valle Saldaña, nativo pacense, médico radicado en Amsterdam entre los años 1730-1750+. Sus obras múltiples llevan fechas de 1734, 1748 y $1750 \mathrm{ca}$. Todos son cancioneros, y pertenecen a la Colección del Portugees Israelitisch Seminarium Etz Haim, Amsterdam, hoy dia en préstamo extendido a The Jewish National and University Library, Hebrew University, Jerusalem. En el Catalog of the Manuscripts of the Bibliotheca Rosenthaliana/University Library of Amsterdam (Leiden 1973 (I), 1975 (II)), se ofrece una mínima información y nada de comentario referente a las obras poéticas de Saldaña: «colección de poesías amorosas en español» ${ }^{4}$. El manuscrito Hs

2 Tópico abordado en la sección, “El autorretrato burlesco» (ps. 131-5), dentro de mi Anastasio Pantaleón de Ribera (1600-1629): ingenioso miembro de la República Literaria Española (Madrid 1980).

3 Ed. consult., Enriquez Gómez, Antonio, El Siglo Pitagórico y Vida de Don Gregorio Guadaña, edición a cargo de Charles Amiel (París 1977). Para ejemplos de la religiosidad o creencias judaizantes de Enríquez Gómez, consúltese, EnRiquez Gómez, Antonio, Romance al divín mártir, Judá Creyente [don Lope Vera y Alarcón] martirizado en Valladolid por la Inquisición, ed. Timothy Oelman (New Jersey, Associated University Presses, 1986), cap. 2.

4 Las signaturas para las obras de Saldaña son: Hs. EH 48 E 16, E 9. 
Ros 298, titulado Poema Afrodiseo y que estudiaremos a continuación, resulta ser "una rama desprendida del potente tronco" (en terminología del maestro Montesinos ${ }^{5}$ ) de las numerosas series de "vergeles", "ramilletes", "flores" y "jardines" que se compilarían a lo largo de los siglos XVI y XVII, y especialmente en Barcelona ${ }^{6}$.

Rezuma influencias de Góngora, Quevedo y del cancionero de burlas español (y portugués) de finales del medievo hasta mediados del siglo XVII. Reanuda asi - con por lo menos noventa años de atraso- una tradición literaria y textual muy castiza. Es decir, este cisne del Amstel, Saldaña, escribe con su Poema Afrodiseo nada más que otro - pero tardíoCancionero de obras de burlas provocantes a risa (Valencia 1519) ${ }^{7}$. El suyo es un florilegio de poesías donde se describen y se aluden a los detalles más minuciosos de la relación carnal entre la pareja. Cuando su benemérito autor médico proclama, "Tú, Poema, navío nunca visto / ni jamás de pilotos governado" (pág. 52), o le toma el pelo al destinatario, o se engaña. Ahora bien, Saldaña no estaba en España, donde el conocimiento de la historiografía literaria del Siglo de Oro era harto sabida.

Las obras de Saldaña - un poema epitalámico (1734); una poesía épica de tono jocoserio, "La Carnisida" (1748); y el Poema Afrodiseo, cancionero de casi un centenar de poesías hasta pornográficas (1750 ca.)restaron en forma manuscrita tal vez por su fuerte carácter profano. Según nos informa el investigador Israel Révah en su estudio «Les écrivains Manuel de Pina et Miguel de Barrios et la censure de la communauté judeoportugaise d'Amsterdam" ", ciertas obras profanas de estos dos literatos mencionados fueron censuradas, fue prohibida su reimpresión, y fueron confiscados sus ejemplares por mandato de los Parnassim de la congregación de Amsterdam. Si las circunstancias fuesen semejantes luego se entiende cómo las obras de Saldaña no llegaban a prensa.

En fin, he aquí dos documentos literarios, el Rato de plalcler y coloquio de damas (Amberes 1708) y el Poema Afrodiseo (Amsterdam $1750 \mathrm{ca}$.), cuyos autores respectivos aparentan ser judíos practicantes. Soldaña pudo haber sido criptojudío; en cuanto a Fonseca, es lógico que fuese

\footnotetext{
5 MONTEsinos, José F., ed. Primavera y flor de los mejores romances recogidos por el Licdo. Arias Pérez (Madrid 1621; Oxford, Dolphin 1953), pág. L.

6 Fenómeno estudiado en mi «Poesías erótico-burlescas en español del Ms. 9 del Ateneo Barcelonés: Jardi de Ramelleres, Criticón (en prensa).

Madrid, Akal, 1974.

a Otsar Yehude Sefarad, VIII, págs. 74-91. Referido por KaPLAN, Yosef, From Christianity to Judaism: The Story of Isaac Orobio de Castro (Oxford, PU, 1989), págs. 129-30.
} 
sefardí marroquí trasladado a Amberes. Ambos son desconocidos en los manuales de literatura española y sefardita.

Las conclusiones a las que se propone llegar en este estudio introductorio son las siguientes: 1 . Los dos autores producen obras representativas del hiperbarroco español, época responsable por una mayor intensidad cuantitativa si no cualitativa. No exentos de gracia en el discurso y del control del concepto verbo-mental (especialmente en Saldaña), Fonseca y el médico de Amsterdam ocupan los registros o escaños inferiores del Parnaso Español. Sin embargo, están alli con ganas de escalar el Monte; 2 . A pesar de una imitación de fuentes/fondos ya arcaizantes, estos nuevos manuscritos representan un intento por perpetuar la grandeza del Siglo de Oro español. No se crearon en un vacío; 3. La intencionalidad de estos dos literatos menores era la de escalar el Parnaso: de que la FAMA les proclamara el ingenio. Adjunta a esta "agenda" puede que haya la de rivalizar el éxito perenne de Quevedo ${ }^{9} ; 4$. En las poesías de Saldaña se ejemplifica una nueva expresividad científica, tipificante de la época pre-enciclopedista; 5. Ambos autores evidencian peculiaridades lingüisticas, con ahora vocablos del francés y del holandés, arcaísmos (en Fonseca), lusismos (en los dos), errores de deletreo (Fonseca), y el uso de un seseo extraño (Fonseca) - rasgos éstos descomunes a la lengua castellana del siglo XVIII ${ }^{10}$.

Para concluir esta descripción de los textos y como puente al Apéndice de láminas que nos ayudará a apreciar tales conclusiones, recurro a las estimaciones de don Juan José Porcel (1750), fiscal de la Academia del Buen Gusto Madrileña. En el Juicio Final de sus cortertulios (la obrita es un vejamen de academia) ${ }^{11}$, el YO narrativo presenta una fuerte apología por estudiar, publicar y así recobrar del olvido la literatura española aún inédita:

Desde esta pieza se registraba gran parte de otra no menos regia, que servida bibliotheca, la qual constaba, según se me instruyó, de todas las

- Cuestión abordada en mi «El Barroc literari català i Castellà: contextos, textos $i$ intertextos", El Barroc Català (Barcelona: Quaderns Crema, 1989), pág. 522; también en la introducción a mi trabajo sobre el poeta Gualbes, Joan Bonaventura de Gualbes i Copons (1643-1714): Obres (Montserrat, en prensa), "Introducción".

10 Véase LAPESA. Rafael, Historia de la lengua española (Madrid, Gredos, 1985), cap. XVI, EL JUDEO-ESPAÑOL y el cap. XIV, EL ESPAÑOL MODERNO.

11 MS 18476/13 de la Biblioteca Nacional de Madrid. Una edición diplomática de este manuscrito aparece en el Apéndice a mi «Aproximación a una teoría del vejamen de academia en lenguas castellana y catalana, siglos XVII-XVIII: de las academias españolas a la Enciclopedia Francesa", en el volumen de Actas del seminario, DE LA ACADEMIA A LA ENCICLOPEDIA (Valencia: Institut Alfons el Magnànim, en prensa). 
obras poéticas de los españoles, añadiéndome que era mucho más y mejor lo manu-escripto e inédito, que lo que avia fatigado las prensas: que de este mal eritendido recato pendia en gran parte el descrédito de la Nación para con las extrangeras, no sólo en ésta, sino en las demás partes de la literatura, porque si vieran los thesoros, que sin ser avaros guardan unos por ignorantes, y otros por indiscreta Desconfianza, tal vez nos restituyeran mucha parte de lo que con el crédito nos usurpan: ipero ésta es Fatalidad lamentada siempre, y evitada nunca de la España!

A continuación unos ejemplos de nuevos textos escritos por sefardíes en el exilio, códices que comprueban una vez más que "Literatura Española" y "Literatura Sefardita" no son términos mutuamente exclusivos. 


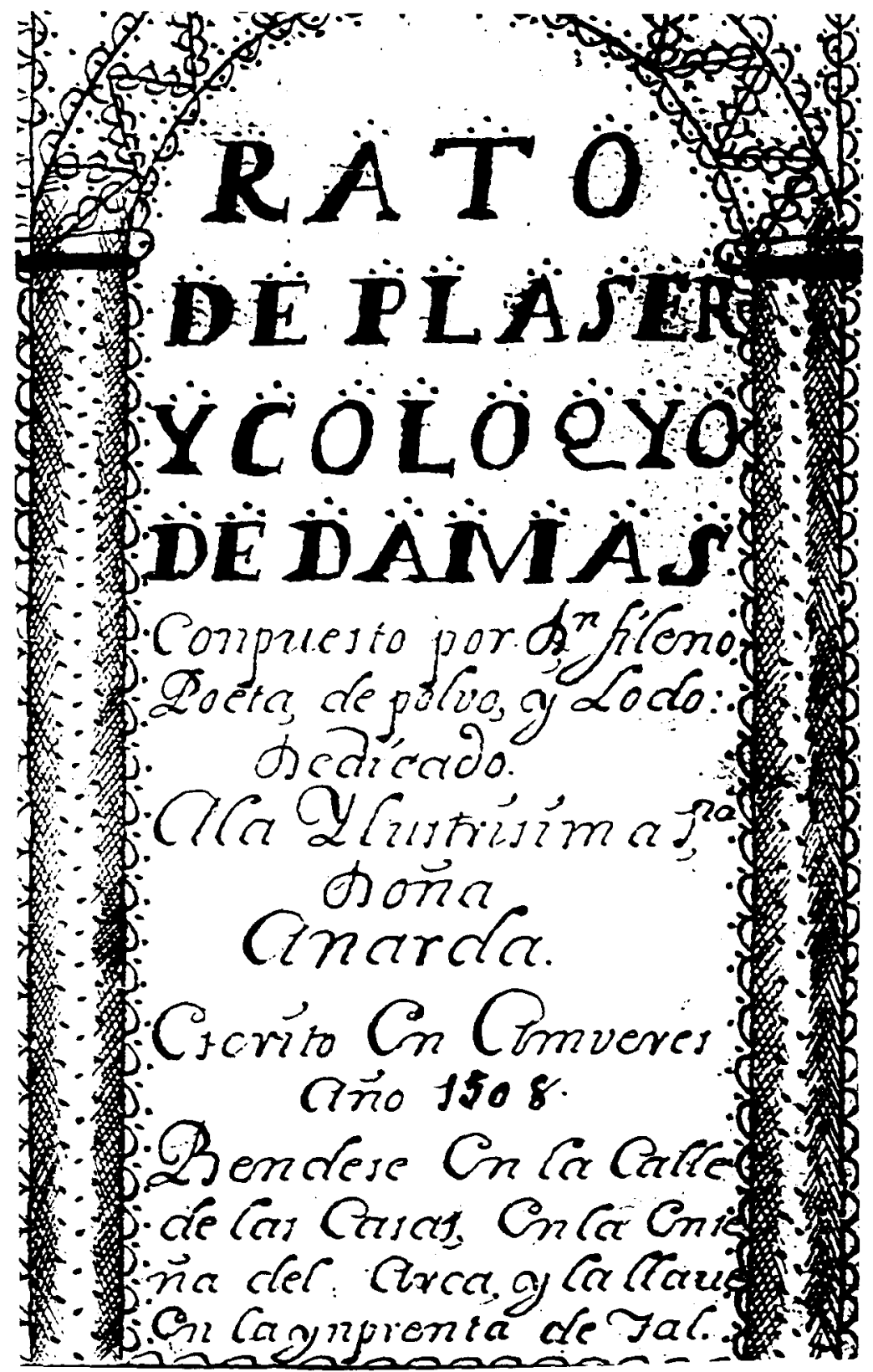

Portada del Ms. 18.156 BNM. Nótense los errores de deletreo ("Plaser», "Coloqyo») y la fecha configurada. 


\section{Cienfin Ju Cara Jintia por no cencter por Giodeos mas.. Cona-gue porpurim a fuede Jerbir aru chectrino.}

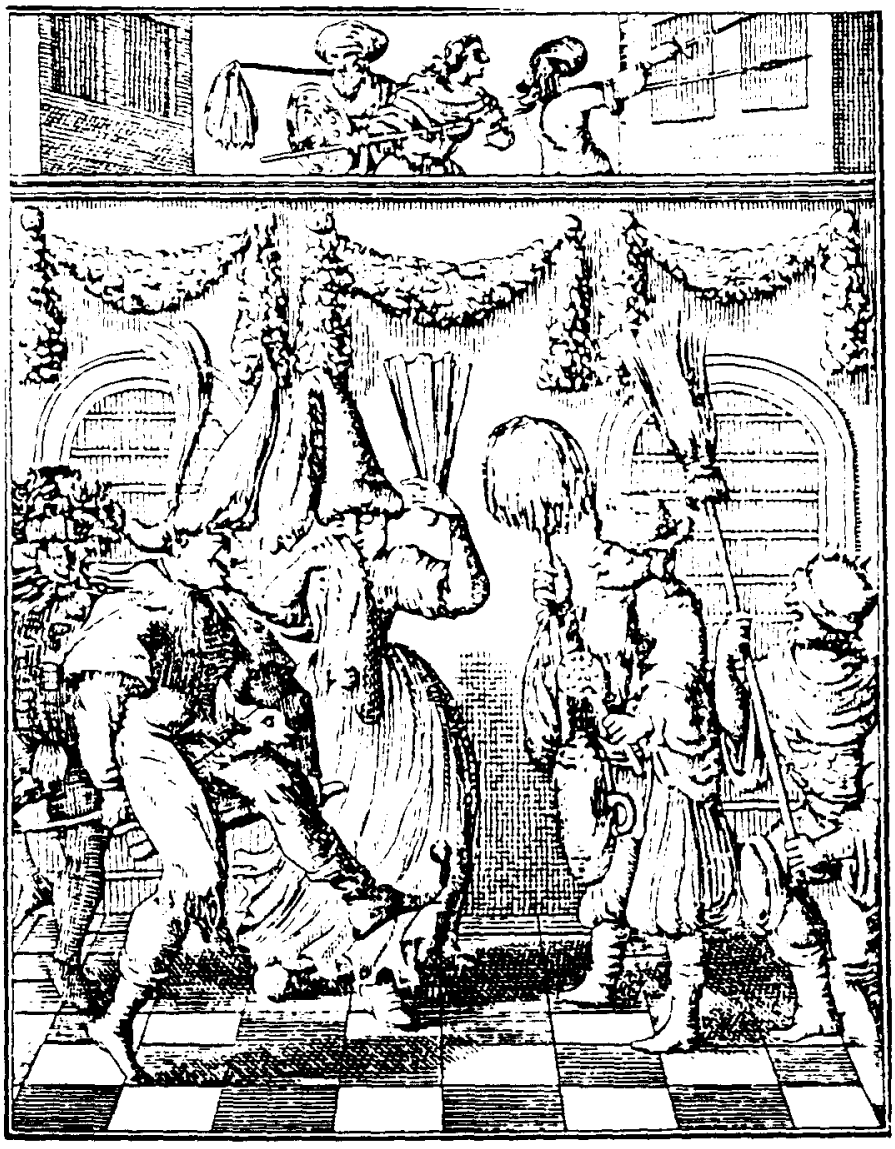

Puilut l'tisels.

Indicación interna del judaísmo de su autor: el juego de palabras se basa en la frase "máscara que por Purim / puede serbir a su dueño». (Lámina reproducida de The Jewish Encyclopedia, Vol. X, s.v. 'Purim'. Aquí se ven "máscaras que por Purim pueden servir a su dueño»). 


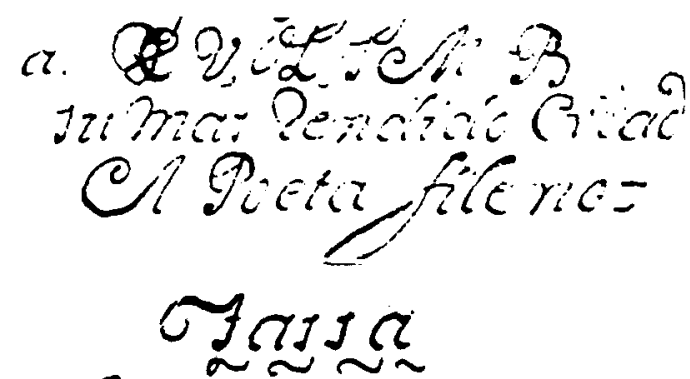

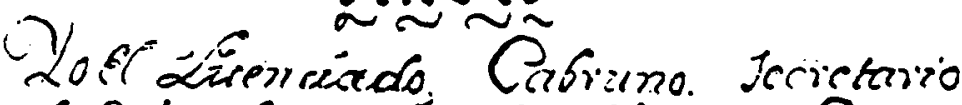

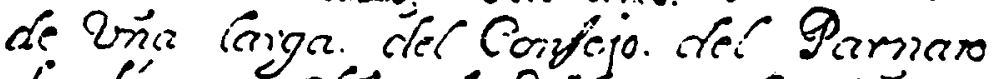
doy fé. que cibiendo qiato par Ca: Joñonat

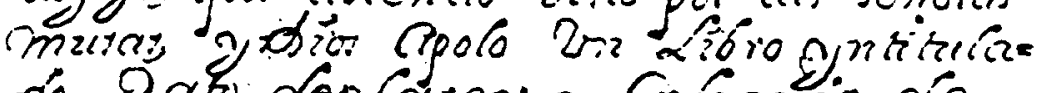

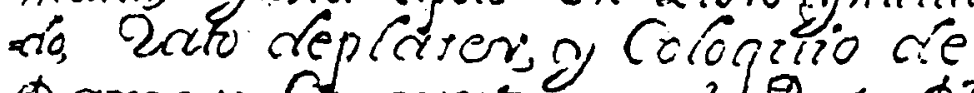
o amat: Cempuerto por el $\theta_{\text {cera }}$ on ticno. hatrial ae Teriami Jasaton - las dirfa: Jeñorar Carla pliego díel disko Nibio. alogue gurjeten rarpor Cl. griesie prestio. yno mat carc mane

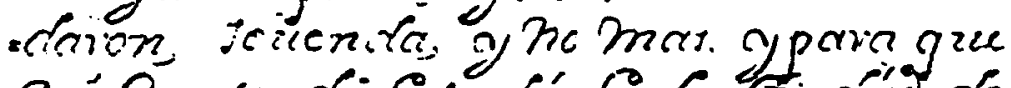

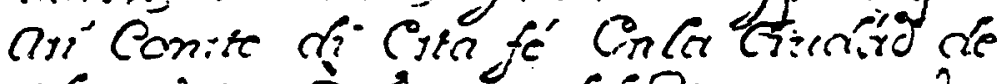
nícaudete iprimero des haes payicres

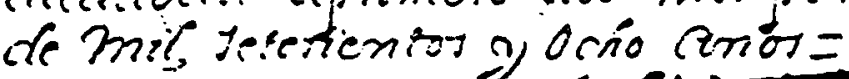

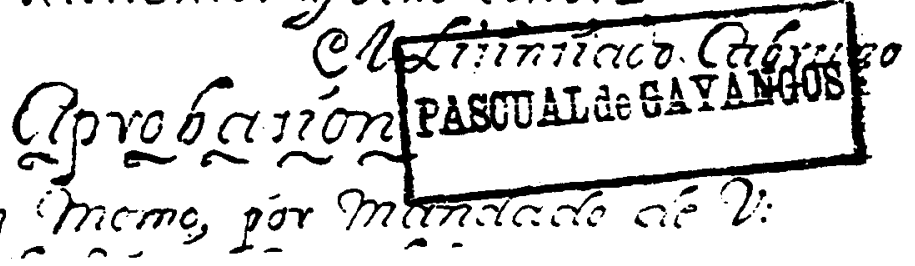

Tassa de tono burlesco, que contiene la invención onomástica absurda típica del Barroco e Hiperbarroco españo!. 
Drologi Or Letor Pomo tira hre

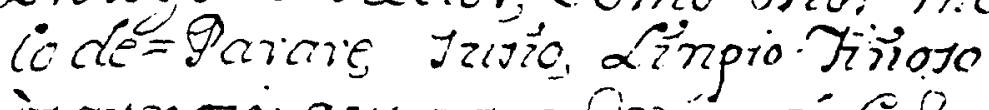

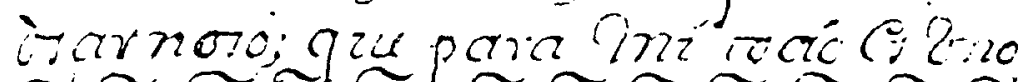

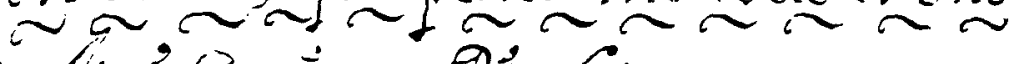

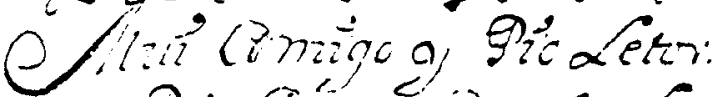

po: Ot Conpere Mrate Letr Cin hombre

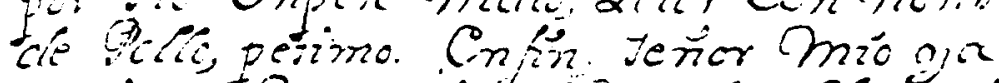

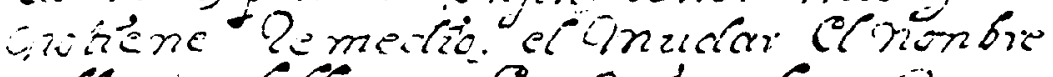

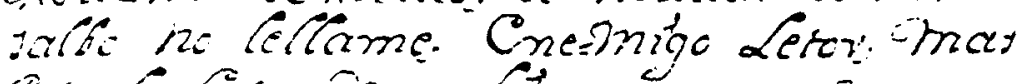

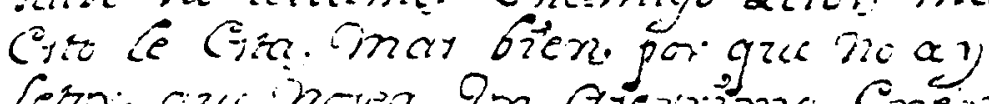

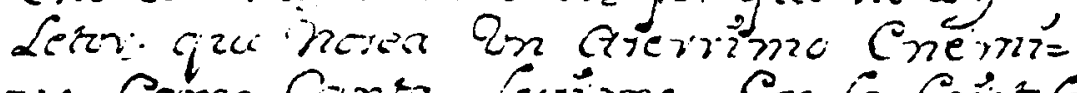

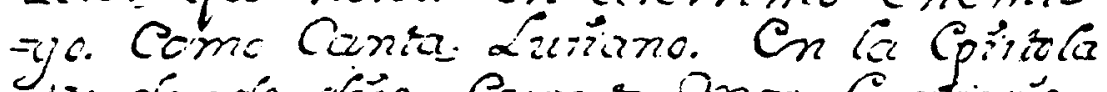

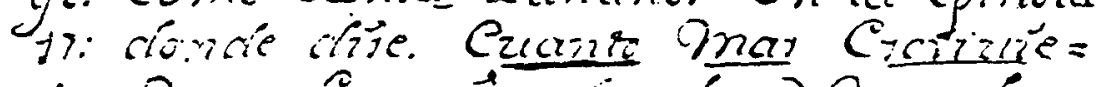
- rev mar conemigo icndian) mar de

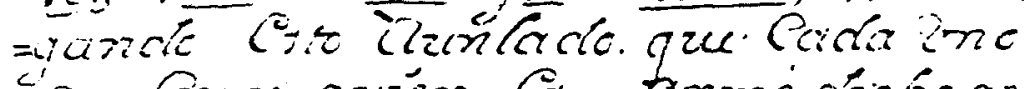

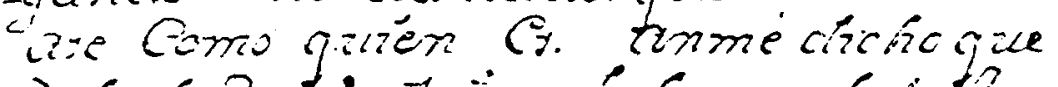

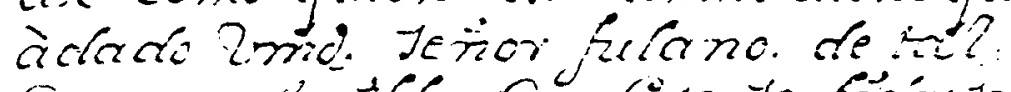

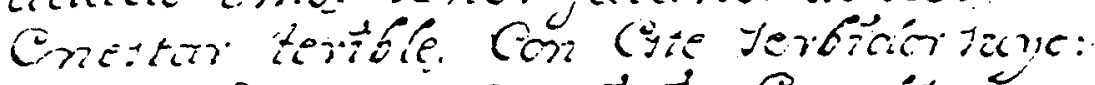

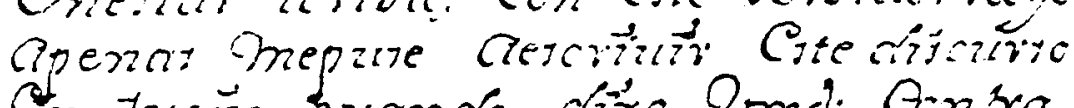
on ticeño furancio chizo Omd: Enira

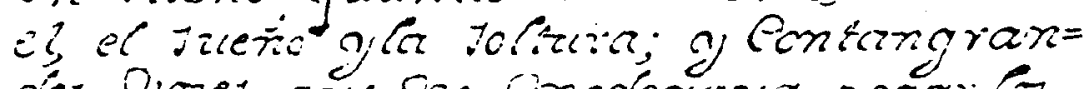

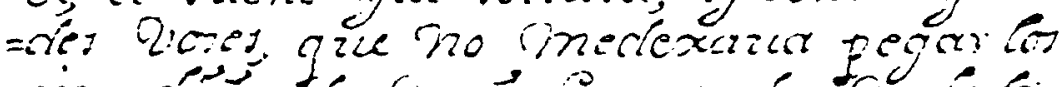

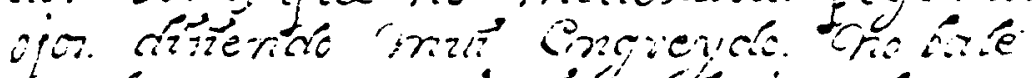

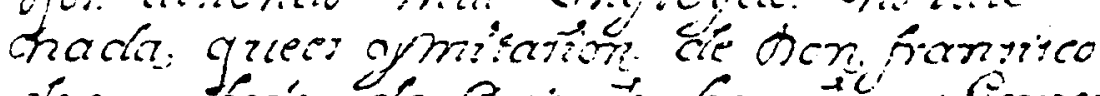

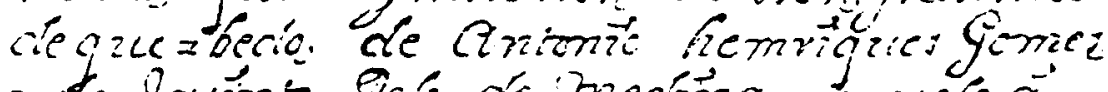

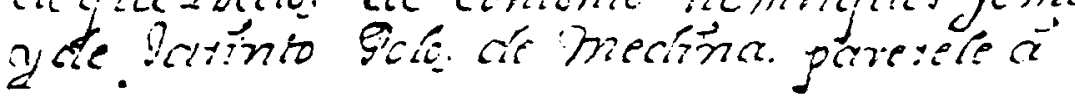

«Prólogo", a imitación del de Quevedo, a "El alguacil endemoniado". Indicación de inspiración literaria: Quevedo, Enríquez Gómez y Jacinto Polo de Medina (en su Hospital de incurables). "Hemriques" puede ser un lusismo. 
88 Oosas, qui jon, Pobrera, Pmbre, ylo Crra, que iniz tanto tomperies que tas hes

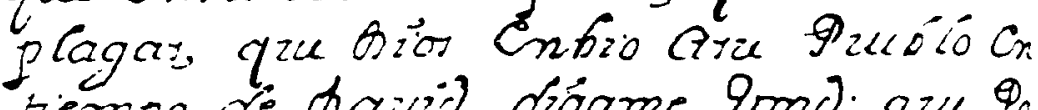

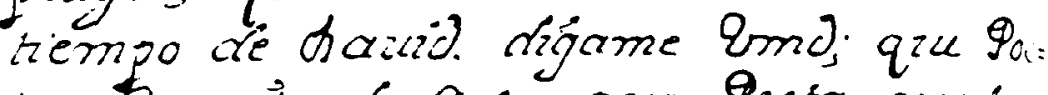
=ta, tonzrio de lyzo. que soera, of =tamento. que Poeta, ho hruizo. Furo.

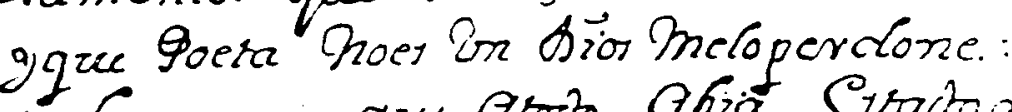

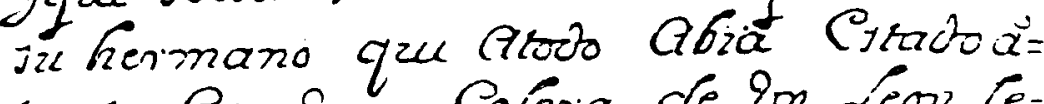

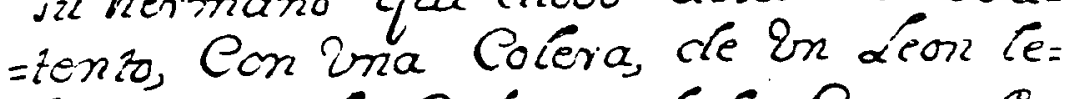
- 6antando la Pabrua de la Pama li

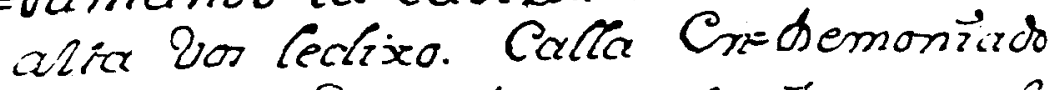
tererio, que heresiay que te tanararibia malaijience aengua, poi las blafemi: - cis que Ponira la Janta Religio porica aritico.

-Pues, scroor diablo - tijo el poeta-, ique puedo hacer in que soy un develichado $y$ un pobre:

$Y$ respondici aquel eiscon de carne hecho una furia:

- Valga el cliablo a a quien lo parió mil veces écl ser polire le parece poco: :Que más queria ser que polire picarion? Ciosa tan de aire es el ser polbre? Picarn, el que es Imorracho no es mais que borracho; el que es ladrón solamente es ladron; el que es juctio tasadamente es judio: pero el que es pohre es lacirin. borracho, necio y judio, $v$ todo cuanto hay malo io es un pro. bre; demas que vos con vuestras locuras os andabais dando que reir a la republica. SNo sois vos el que andalais tocta la vicla por la ciudad pregonando uquién se hubiere hallado el es. trito de la paciencia, que todos dicen que le han perdidony cuando no hav un hombre que se haya halladto y no sicquicrat,

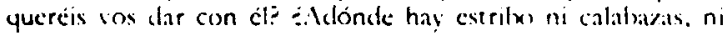
que estribo es éste ni que haca? : Vos no sois el que tomasteis la eerna conera la makdita, y en oyendo ofulane soleo ha matctiram ilans vos a querer ararlae bil verdaderos soltarse la maldita

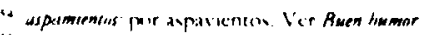

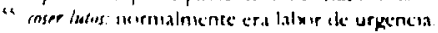

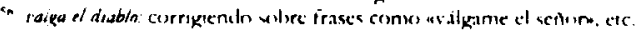

Imitación por Fonseca del siguiente texto de Polo de Medina, Hospital de incurables (ed. Cátedra). Vale destacar que el autor judio censura los comentarios despectivos a lo judio en su propia obra. 
come de pertañay: Uná 'hariz, de 120 perro chino: Con lina Qoca, peonique Ca clec ginfierno. una Barba mar joficacicz, de Eaziello quec la jierra

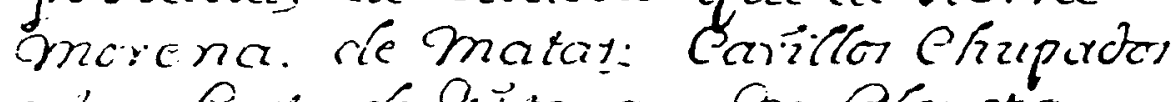

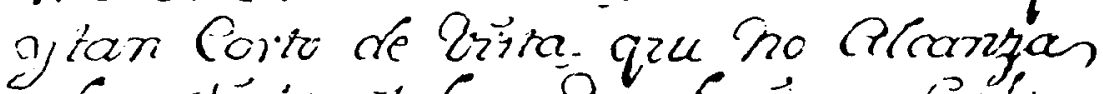

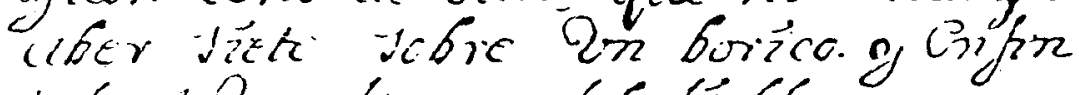
ivdo el Ona figrara der diciblo.

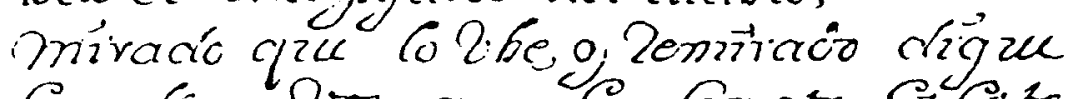

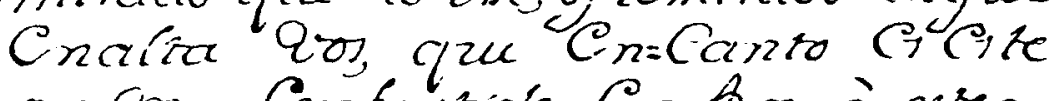
oro me Conbericlo in hon, o erres hombre. Comi Pescrto. 0 oho tegundo

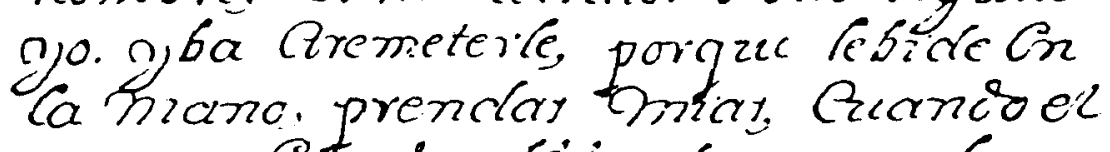
sepus Conpie. disiendíme que bunca. auzi" deniro. bueno Geno le Respondi.

El YO narrativo se encara con su doble íncubo. Se asemeja mucho esta escena a otra que pinta Pantaleón de Ribera, en su "Vejamen de la Luna", 1625/1626. (Madrid: Porrúa, 1980), ed. mía. (Ver página siguiente). 


\section{Anastasio Pantaleon}

Sulimos désta, y llegamos a otra cuadra, donde vi de espaldas un estudiante, leyendo un papel impreso, [32r. | cuyas letras muyusculas (que eran las que de lexos se podian leer) deçian: Mas I Mas?l otro çriamion. 2s Luego que sintio desasosegarse. trsiomo una silla, en que estava, y vile (Dius nos libre) cara a cars. Tenia el rostro, ni mas ni menos que este mio, y pegado tcumo yol al ojo izquierdo un antojo, tan embaracosamente yue pur traherle solo, tenia una mano menos, como quien vene de la guerra. Dixe luego entre mi, " $i$ Vaigame el dios de ton exérşitos! ¿quien mie ha subido acá el espexo; que si es to no $M$ sido, sin duda tengo en esle mundo algún meltiço?" $Y$

preguntando a Don Alunso ¿quièn era? me respondiur a mismo estudiantillo: "Yo os lo dire, escuchad:

$$
\begin{aligned}
& \text { Mi montere es lontaletin: } \\
& \text { si vien conpeturas mias }
\end{aligned}
$$

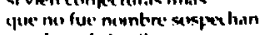

$$
\begin{aligned}
& \text { apando si de la pila. } \\
& \text { Himbre tan de luerias faldas } \\
& \text { yue suill me desentliga } \\
& \text { de muger el nocalcarme } \\
& \text { ince dedos de taugia. } \\
& \text { Algou Abenamar mi meto } \\
& \text { y mii ter algat } X \text { arila } \\
& \text { al artitno de un espepo } \\
& \text { ni me acus,m, ni me litran. } \\
& \text { Negeri texde el ame el trage. } \\
& \text { mas yue mi vista me tizira, } \\
& \text { allow soy de la biveta }
\end{aligned}
$$

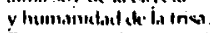

$$
\begin{aligned}
& \text { Espuntu shy de un respuiem, } \\
& \text { yee en la pnotesioin jursta } \\
& \text { me graduc de hinesto" } \\
& \text { Buchiller pur ho evira vida }
\end{aligned}
$$

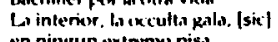

$$
\begin{aligned}
& \text { en ningun ext nemm pist. }
\end{aligned}
$$

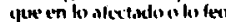

$$
\begin{aligned}
& \text { jamas el medin " peliyara." }
\end{aligned}
$$

"Teneos (dixe), liçençiadu, que basta hurtarme ba figura, sn que hagais el mismo ladroniçio en el romance". "No hurto de nadie yo (me respondio con gran confianca) que si tubiera ow inclinacion, no la gastara en hurtar cosa tan mala, cormo v/uest|ra figura". "Pues, picaro britum, (te dixe) ¿no bastava la desvergüenca, sin ariadir el denuestu? ¡Vive Dios, que he of cruçarte toda esis caria, si (cmk) estás en el Orte de la Lund. estubieras en su mismu cuterno!" Apernas le hube diktu lo maldita palabra, quando me dixu: "Guilón menguado, yo te is cruçaré, y será de Carabaca por más serias; pero para que $k$ entretengas con una pisa de moxicones, ve numiandu lus yur se siguen". Cerró connigo, y yo con êl, tan desapiadada. mente, que cada [33v. I porrazo, nos hechaibamox las nariger una legua mis arrivica de demde sucedia la penckencia. No

Nustava Don Alunso a ponernos en paz, por que estivamos mus encamicadios upue Don Nicotas de Prada, el qual, oyendo Anuido, solio de su baina, y Corriblano de su cámara diciendo: uriures, jueguen descle fuera, y miren que no bale brazal". fro el fingido Pantalecin me llovia las manos a esta comisura ude que, a mi parecer, quedé medio calvo) y yo le graniçaba bs mus a aquellos ojos (de que a su parecer quedó tuerto) hasta yur metiendo el montante Don Alonso, nos dio miti. y mils. da latigazos. Con el alburoto del que me tocaba en la parmxin, despedi el incutus molesto, y hallíndome en mi casa, di mill gracias a Dirs, de haver escapado de tan pesado suerio

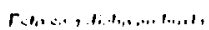


Texto y contexto de dos manuscritos literarios inéditos del siglo xvIII...

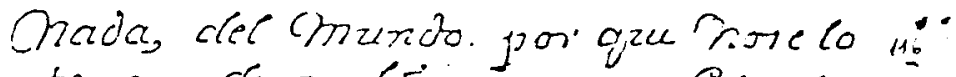
tengo de pribiar porque Grong tar. inogado fon briej que hogrizicia nit cun oys que Jellema, hision mar Conitoo yi cump; Jele anto= gare ligo, tea Goprimero ho acro - clarge cre mi. cremi aporenio afa clore clela juche nicires por la ma= - ñana. abeynte onie clectires para= clo. amieridans punio of eonia.

cmana, Crato; aries a que tero

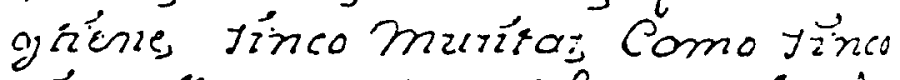
pínpollon, gue ton el Iugere cletoio elparnato para Orén Je Prienle

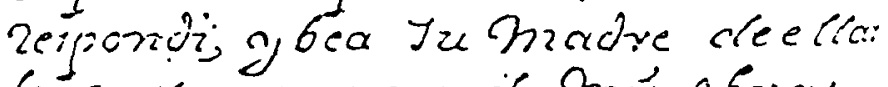
corgusto, gue yo cle Mrs obras

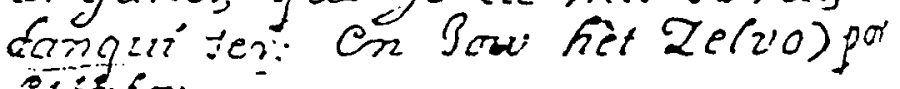
efferso:

Jier garion clière joj cairl Oreve elpuicrio

nunca ade jer derecho quien mario kuento.

Ejemplos del holandés (bouw het zelve $=$ que se edifique a si mismo); de un arcaísmo (garsón); de deletreo extraño (antogare, enogado, ynbiar), para el siglo XVIII; y lusismos (manducas, abuja). (Ver también lámina 9).

211 


\section{casising}

भole erais hias gire coss:

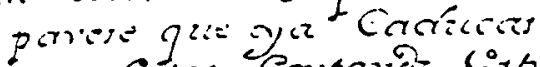

furer Cjtar Contaner costeffer

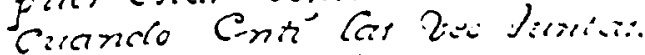

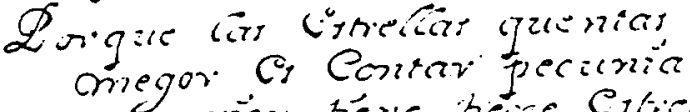

gut guten herse heire Coties:

ogilien: ho la tiene Qyiuns.

Jicamidia horkic lai quesits

C) Jerial gue no Tnandiers

que el Pontarlat atal íora sio abei gue Coner Onincía.

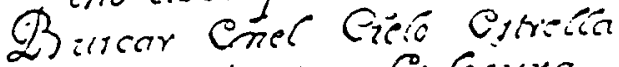
ense zanias Co losura co pumitrio jera fiscaría aze en Impagar Ena labiya.

Gexa de Confar Cotreíis: porgie Jera Goa cína gue Puantas c'sheelest quenisy taniar ze natarn bevigar.

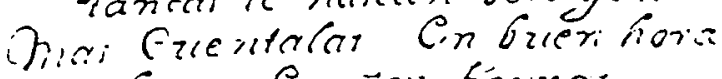

ne Eerar en zar figurars.

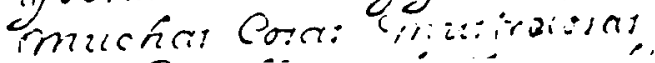




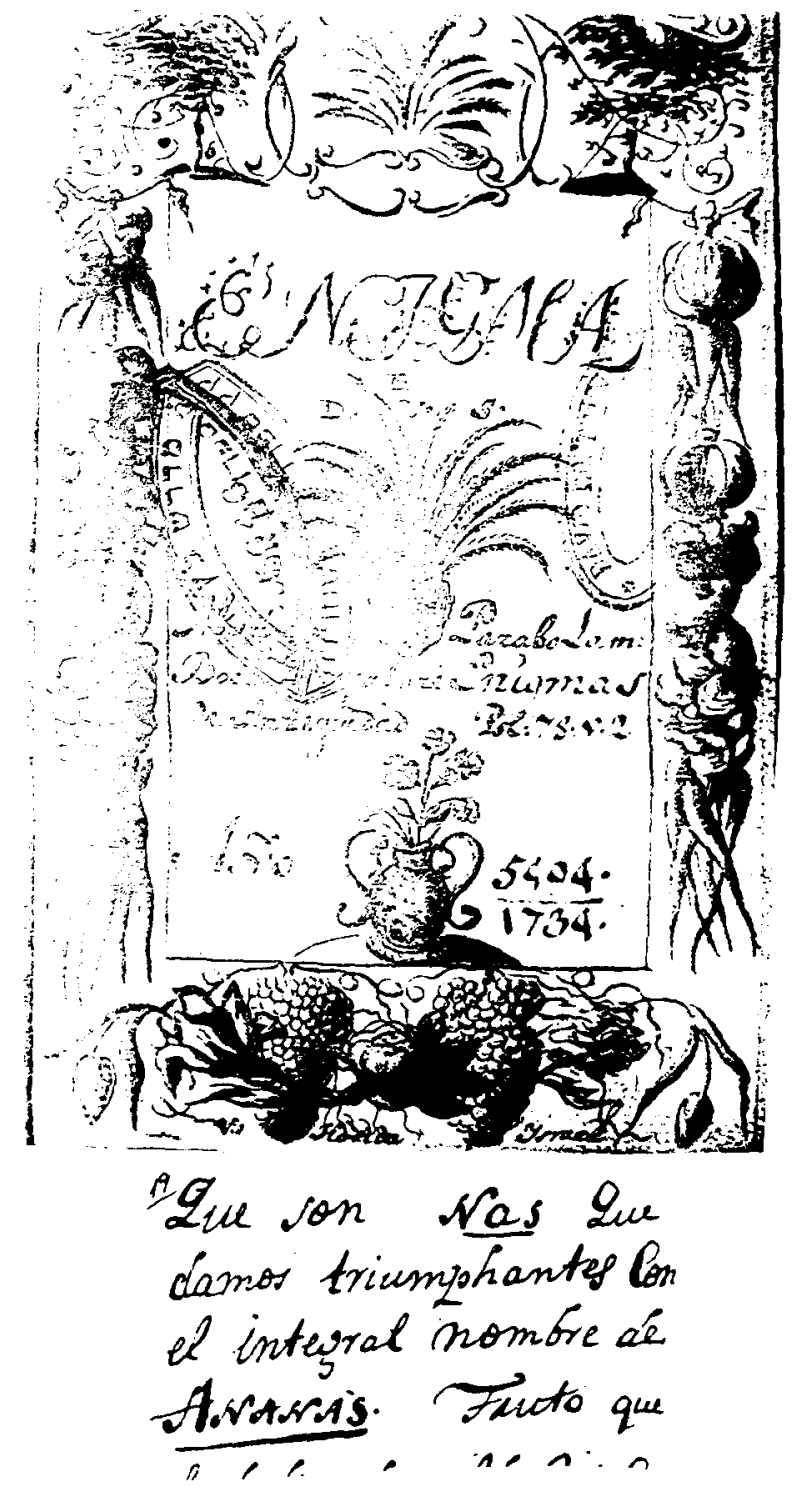

Saldaña empieza su carrera literaria en Amsterdam escribiendo versos panegíricos con propósito epitalámico. Se declara como judío profeso al recurrir a la fecha según el calendario judio.

El emblema del ananás será una representación de la copia de fruto (la piña) para así bendecir los frutos (niños) del matrimonio.

Puede que "Ananás" sea otro anagrama para 'Saldaña', además de 'DVS' y "Lasnada». Todos parecen ser epónimos. 
KENNETH BROWN

r.

Los.

Los Señores

Arov, ishace, y iació

Drevid alc Ginels.

Breclaros Edificadore.

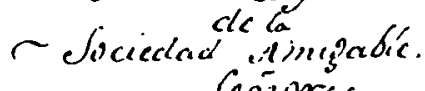

ecinores

$\alpha a \sim$

- Carnisida

rucmea

rocoscrion

- Comsucser

Por.

- Ortor, saldorian

Plo

THustcrdam $\sim$

- conks

-1218.

Mss. Hs EH 48 E 9 y 16 (=Hs. Ros. 297, 298). La SOCIEDAD AMIGABLE debe ser una extensión de las academias literarias, fenómeno éste que llegará pronto al club, sociedad de recreo y casino).

214 
Texto y contexto de dos manuscritos literarios inéditos del siglo xvIII...

$$
\begin{aligned}
& \text { m } \ell^{\circ} \ell \text { m } \\
& \because / l J 1100 \text { cliseo. } \\
& \text { m } 907) 7 c
\end{aligned}
$$

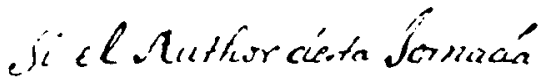

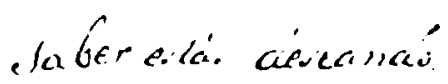
c.gui cotn crevilu; Gimearcé,

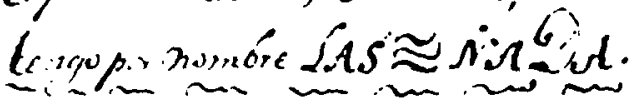

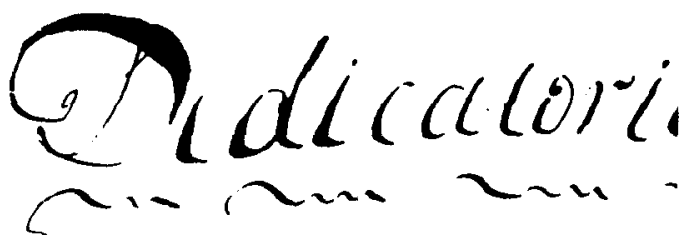

Come entrctudos cs.nora cin al trals Curlcsanci, dy ucle vine átamano, (oms dicern, en buen ira.

“El Afrodiseo» se dedica a Arón (=Nora) Pinto. Los Pinto eran de las familias más económicamente poderosas de Amsterdam en el siglo XVIII. (Véase el estudio de Kaplan, ob. cit.).

215 


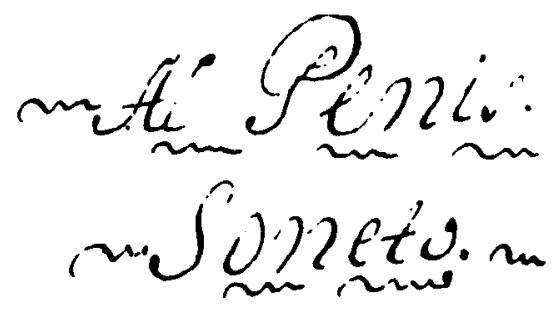

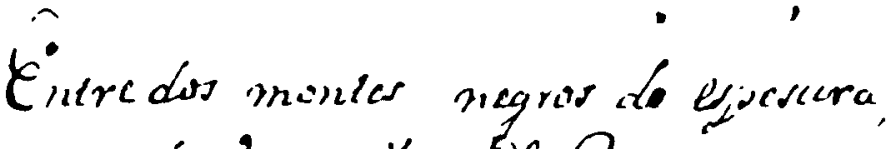

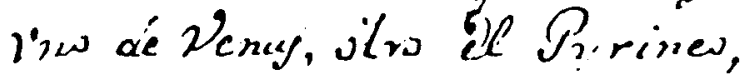

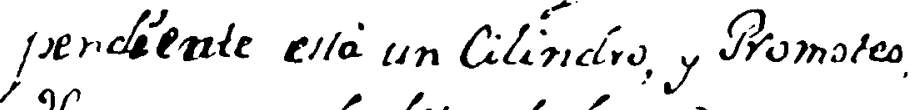

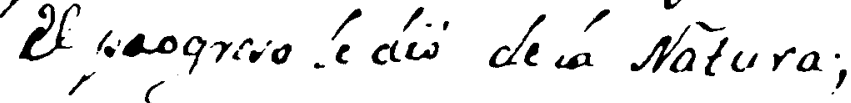

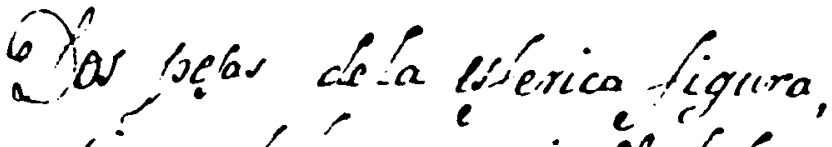

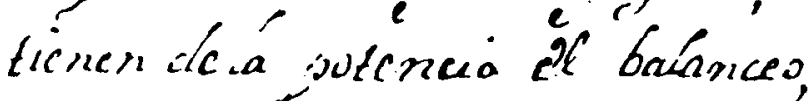
guc siaftriatia epqa alquri inenes, ciecaryounc ex rigiciá estructeres:

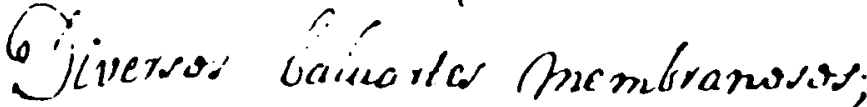

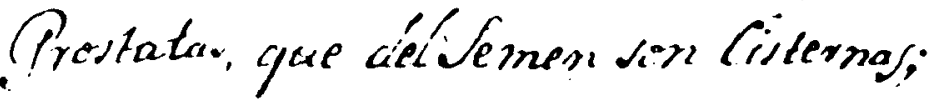
"una (Pintra cís vasos Constricicia;

flaicre entrcíczacló nigitroses,

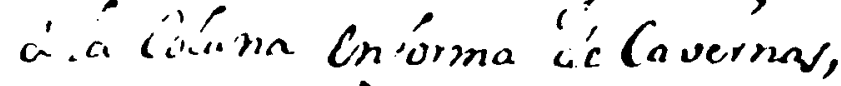

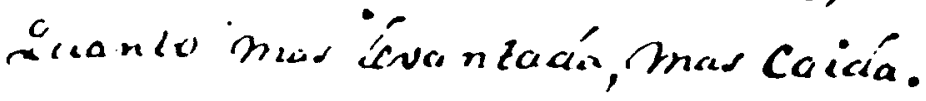

Los dos sonetos que epilogan el cancionero, “El Afrodiseo". Como convención petrarquesca definen el tono y contenido del conjunto: burlesco, clínico y enciclopédico. (Ver también lámina 14). 
Texto y contexto de dos manuscritos literarios inéditos del siglo xvIII...

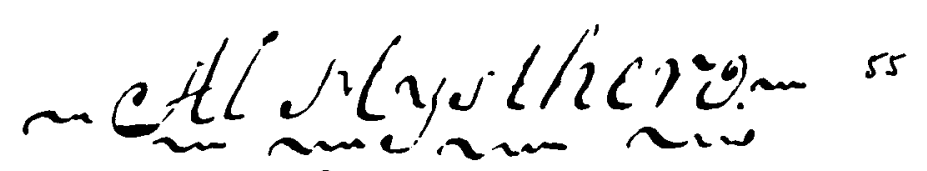

$$
\left.\sim 0101 t^{6}\right)^{m}
$$

Gitic piáres dos ambor tuernosos, $e^{4}$ aum olro que a juiramide Canina, - ie císcuórc una Raia cínnclestina,

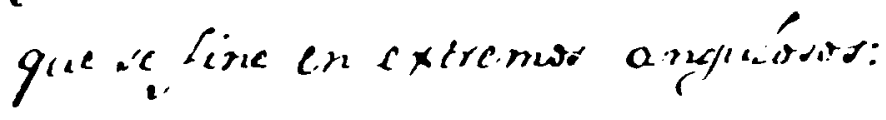

(iivo umbraies íacen escaírosos, pur cas punzar gue digo se termina,

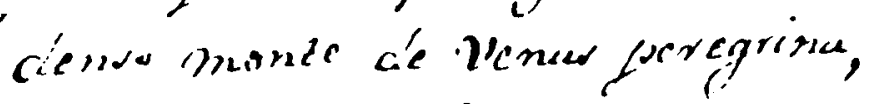
alla Cumbie de lalos amorosos:

Gor receiferar minefor cspongierias, numectar úa reconciita cíanfura, Con: ch Clyter, y Prostatar turgenter;

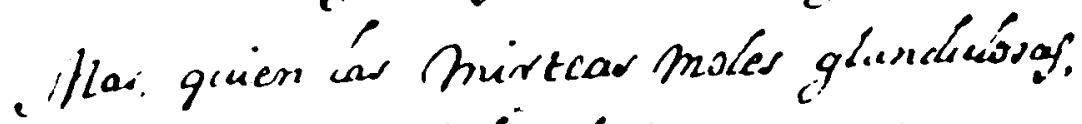
Culivia con Cicinalicica cotructura, Consiguira folix fruetsos nivientef.

217 

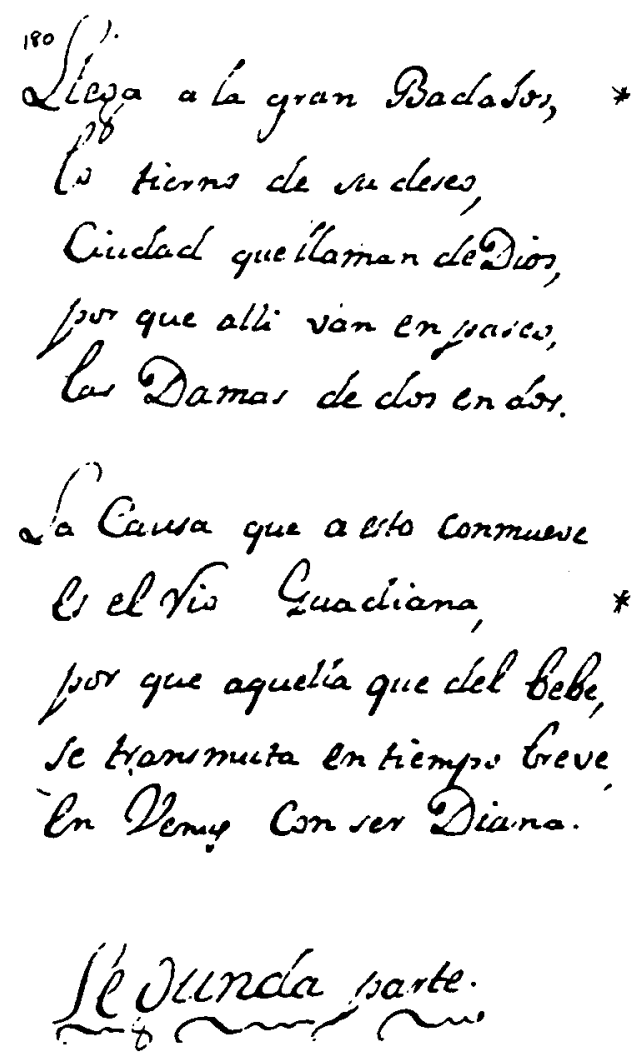

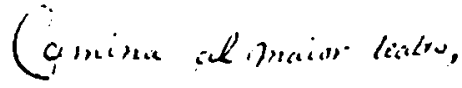

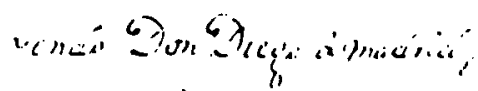

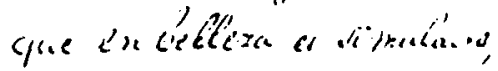

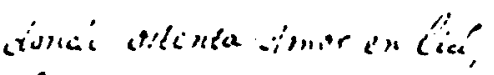

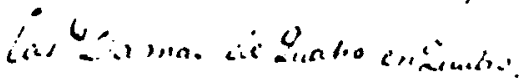

1. De la novela, "Lo que son mugeres" $1{ }^{\text {a }}$ pte. Se encuentra en "El Afrodiseo". Posible alusión al amor que siente el autor por su pueblo natal. 


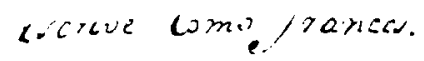

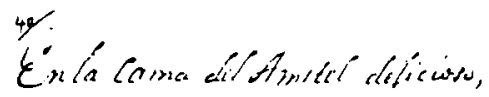

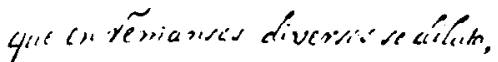

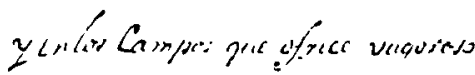

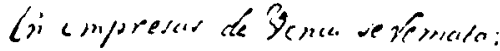

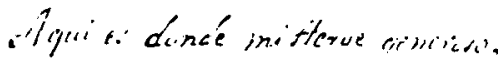

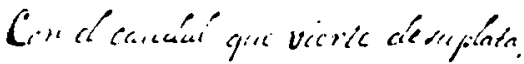

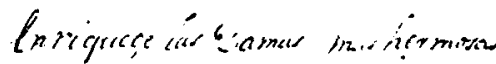

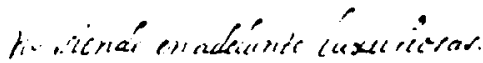

$1-\rho$ are nermirera lan qrancé dé cúppara, b

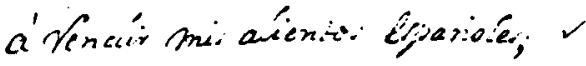
cíxame, pues que ari mata parberi,

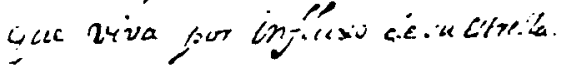

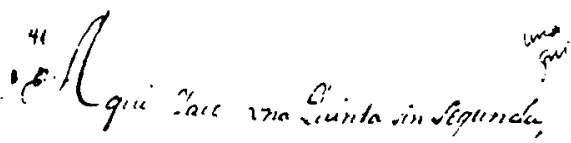

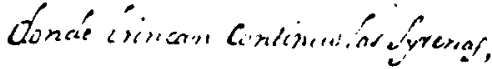

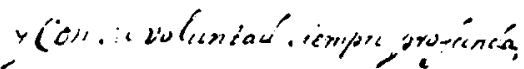

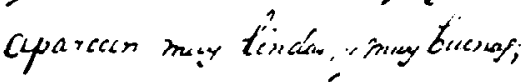

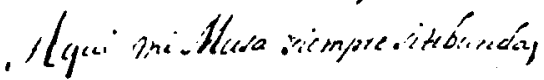

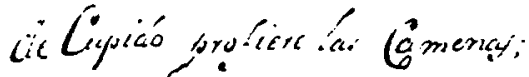

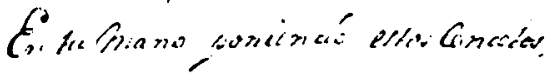

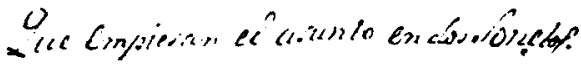

2. Reminiscencias del Tajo de Garcilaso, del Mirarbueno de Medrano, de La Flecha de Fray Luis, del Palacio de los Gelves (Herrera), de la Finca Sabina de Horacio. 